\title{
An Introduction to Online Physical Oceanography
}

\author{
Matthins Tomczak \\ Flinters University of South Australia - Adclaide S.A. AUSTRALIA
}

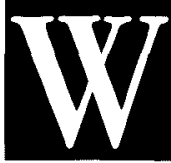

hile marine science appears to experience a boom in undergraduate teaching (if the number of competing introductory textbooks is any indication) anyone involved in teaching marine science as a first year subject will have to agree that in all countries of advanced oceanographic training academic standards at undergraduate level have been on the decline. The reasons for this are complex and many, but there is no denving that compared to their counterparts of 20 years ago, students entering university today come ill prepared in such basic areas as mathematics, physics and chemistry. More and more students enroll in marine science classes, but fewer and fewer students satisfy the eligibility criteria for the study of physical oceanography. Universities try to cope with this situation in a variety of ways, but in a system where the existence of teaching staff has to be justified on the basis of student numbers alone the inevitable result is a "broadening" of the course structure, an euphemism for lowered entry requirements. Student expectations, on the other hand, have risen faster than student numbers-the minimum the students expect for the substantial fees they have to pay is a lavishly illustrated volume of lecture notes.

The development of the first year topic Earth Sciences $1 \mathrm{~B}$ at the Flinders University of South Australia, which comprises Meteorology and Oceanography, exemplifies this process rather well. When I took over the responsibility for the delivery of the oceanography section of the topic from my predecessor 8 years ago, the class of maybe 200 science students could follow simple mathematical derivations and had no great difficulty to document their laboratory experiments with the help of annotated graphs. They were issued with a photocopied set of elementary notes cobbled together from illustrations out of various texts and produced under the rules of "fair dealing" in photocopying. Today's class, somewhat smaller but still comparable in size, caters not only for science students but for students of environmental studies, archeology, globalization, nature tourism and other brands, and a suggestion to display experimental data in a graph, using a simple Cartesian coordinate system, more often than not draws a blank stare as a response.
The lecture notes for the topic had to be adapted to the changing conditions. The change was gradual, and I struggled along, improving my photocopied notes through a slow evolutionary process. As the school budget shrank the school board resolved to charge the students the recovery costs for the printing of the notes. The turning point came in 1995 when the government declared that charging recovery costs was illegal, since the students had already paid their fees and could thus expect to be issued with all necessary teaching material without additional charges.

This caught me (and others) in a real dilemma. I could not possibly announce that there would be no lecture notes for Earth Sciences $1 \mathrm{~B}$ any more, and I could not possibly subsidize their printing from $m y$ research grants. After a few weeks of thought I found an answer: I placed all my lecture notes on the web, thus fulfilling the government regulation of free accessibility, and offered the printed version as optional material for sale. This was the birth of my online teaching material.

The first two years were an interesting experience. Despite all assurances by the media that the young generation, and in particular the educated young generation, is hooked to the internet and shuns books and newspapers, nearly the entire class continued to buy the printed notes. Printed notes have several clear advantages over notes on the web. They can be taken on the bus and to the beach, they can be copied and shared easily, they can be dissected and rearranged to meet the learning needs of the student, they can be annotated. The notes on the web, which at that time (1996) were only book pages displayed on a screen, could simply not compete.

This situation changed within less than a year, again not out of my free will but as a response to regulations. The rules of "fair dealing" that cover the use of photocopied material for teaching purposes do not apply to the web. Placing an illustration on the web is considered publishing and requires the permission of the copyright owner. I therefore had to produce dozens of illustrations of basic oceanographic facts again myself and "publish" them in my lecture notes. This was a painful and laborious process, but in the end the notes 
on the web with all their illustrations in brilliant colours began to look more attractive than the printed lecture notes with their low quality photocopied illustrations, most of which had been copied from copies of copies of copies and were of rather dubious quality.

This lead to my next experience. The students now preferred the notes on the web but wanted to print them all out, take them on the bus and to the beach, copy, share and annotate them. They were quite prepared to spend the extra dollars for printing out dozens of color pages. I consider this a transitional phase, because at that stage my electronic notes where still essentially a book displayed on the screen, albeit with more colorful illustrations which guaranteed a better learning outcome.

The test whether the students will overcome this phase and learn how to use online lecture notes will come later this year with the introduction of the latest version of my notes in class. This version incorporates elements of instruction that are no longer a replica of printed notes but are beginning to exploit the possibilities of the electronic medium. To list some examples, many illustrations, such as the principles of seiches in closed and open basins, the structure of internal waves or the time evolution of an El Niño, are now animations, and the lecture on density and stability now contains an online calculator for seawater density and sound speed.

Further and more radical development came-again -not as a planned activity but as a response to another administrative decree. The teaching of science at Flinders University had always been based on the premise that nothing can be learned without practice. Weekly laboratory experiments were therefore an integral part of first year science training. A few years ago the Faculty invested in 90 computers and set up a "Computer Mediated Learning" (CML) laboratory. As coordinator of Earth Sciences 1B I was told that I had to replace $50 \%$ of the laboratory experiments by computer exercises. Measurements in wave tanks and experiments with layered fluids were thus replaced by sessions in front of computer screens. I devised as sensible exercises as I could. This was a few years ago, before interactivity on the web became a real possibility, so I had to use proprietary software, and under the terms of the license the exercises could only be offered on the computers of the CML lab. JavaScipt has made it possible to achieve the same without that restriction, so during a research voyage in November 1999 I translated all my exercises into HTML and JavaScript and included them in my online teaching material. Up to this point my online teaching material had only been a response to deteriorating teaching conditions. But I made another experience. I had placed my lecture notes on the web without access restrictions. Other lecturers in similarly desperate situations discovered them and asked for permission to use them. That was, of course, the idea of making them public in the first place. I remembered then that several of my former graduate students who had returned to their own countries and taken on teach- ing responsibilities in their departments had occasionally asked me for advice on textbooks, lecture notes and other material. It occurred to me that many colleagues, particularly in developing countries, are likely to be in similar circumstances and would consider my notes a great help for developing their own courses. However, I had seen on earlier occasions how cumbersome and slow a connection to the internet can be in Africa or in parts of Asia.

I could of course burn my teaching website onto a CD-ROM, which even a slow PC can use with good results as long as it has a web browser. But how could I distribute it to its potential users? The solution came to me in 1998. I offered my teaching site as a CD-ROM to IOC/UNESCO for free distribution in Latin America, Africa and Asia (except Japan) and added an announcement to my site's title page that the entire site is available free of charge from IOC/UNESCO (with the above mentioned restrictions).

One aspect of web publishing that has not received clear attention is quality control. We all know that there are mountains of information on the web, but how do we know which information we can trust? Being aware that my material is spreading over all continents, I am trying to keep up an acceptable standard by asking colleagues to review my material. This is not quite the same as anonymous peer review, but it is the best I could arrange as the author. To give reviewers some acknowledgement for their willingness to participate in this experiment I include their names in my online material.

The CD-ROM has clearly been a success. IOC receives a constant stream of requests, and the response from users is overwhelming. Following a request for a Spanish translation I established contact with four colleagues in Latin America who, in collaboration with myself, are presently working on the Spanish version. We expect to have a bilingual English/Spanish CDROM ready for distribution later this year.

In the meantime, interested colleagues have full access to the lecture notes, exercises and Spanish translation as it develops at my website http://www.es. flinders.edu.au/ mattom/IntroOc.

I welcome suggestions, proposals and comments. I consider my website a novel addition to the teaching of physical oceanography but leave it to others to comment on its value. My own feeling is that it languished for several years as a cheap substitute for proper printed notes but has now matured to the stage where it can stand on its own feet. The concept clearly has much potential, and my site could certainly by of much better quality if we would operate under the staffing levels and working conditions of the 1960s or 1970s and not under the constraints of the year 2000. As it is, I can only develop it during short periods of leave from the trenches where my colleagues and I are trying to defend acceptable standards of science education. 